\title{
Competência em informação e suas raízes teórico-epistemológicas da Ciência da Informação: em foco, a fenomenologia
}

\section{Djuli Machado De Lucca}

http://orcid.org/0000-0003-4505-0688

\section{Elizete Vieira Vitorino ${ }^{I I}$}

http://orcid.org/0000-0003-2462-6553

I Universidade Federal de Santa Catarina, SC, Brasil.

Doutora em Ciência da Informação.

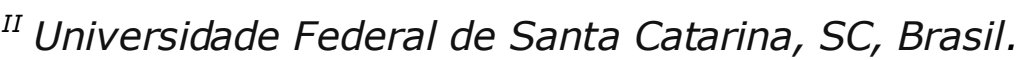

Professora do Programa de Pós-Graduação em Ciência da Informação.

\section{http://dx.doi.org/10.1590/1981-5344/3317}

A competência em informação é um movimento social e científico, que investiga os processos referentes à busca, ao acesso, à avaliação, à comunicação e ao uso da informação. Como movimento científico, integrou-se à Ciência da Informação, que emergiu a partir do problema da sobrecarga em informação e das dificuldades em recuperá-la. O artigo propõe investigar a relação epistemológica entre a Ciência da Informação e o movimento científico da competência em informação. Identifica-se, na ciência da informação, a existência de três paradigmas, apresentados por Capurro (2003): paradigma físico, paradigma cognitivo e paradigma social; e também três vertentes epistemológicas, oriundas da sociologia, indicadas por Araújo (2003): corrente positivista/funcionalista, corrente crítica e corrente social. 
Com base nas propostas de Capurro (2003) e Araújo (2003), concebe-se a existência de três vertentes de pesquisa sobre competência em informação: a vertente cognitiva, com aproximações funcionalistas e positivistas, a vertente social e a vertente crítica. Essas aproximações epistemológicas orientam as investigações que atualmente são desenvolvidas na temática. Por fim, argumenta-se em favor da fenomenologia enquanto princípio teórico-metodológico congruente às pesquisas em competência em informação, visto que a informação é um produto político, revelado no social, que sofre interferências do mundo externo.

Palavras-chave: Competência em Informação; Fenomenologia; Teoria; Epistemologia; Metodologia.

\section{Information Literacy and its epistemological roots of Information Science: a focus on the phenomenological approach}

Information literacy is a social movement and a scientific field that investigates processes related to the search, access, evaluation, communication and use of information. As a scientific field, it is integrated into Information Science, a science which has emerged from the problem of information overload. The article proposes to investigate the epistemological relationship between Information Science and information literacy as a field of study. The existence of three paradigms, presented by Capurro (2003), is identified in the information science: physical paradigm, cognitive paradigm and social paradigm. Also, there are three epistemological aspects, coming from sociology, indicated by Araújo (2003): positivist / functionalist approach, critical approach and social approach. Based on the proposals of Capurro (2003) and Araújo (2003), we conceive the existence of three strands of research on information literacy: the 
cognitive aspect, with functionalist and positivist approaches, the social aspect and the critical aspect. These epistemological approaches guide the investigations that are currently being developed in this area. Finally, it is argued in favor of phenomenology as a theoreticalmethodological principle which is congruent to research in information literacy, since information is a political product, revealed in the social, that suffers interference from the external world.

Keywords: Information Literacy; Phenomenology; Theory; Epistemology; Methodology.

Recebido em 21.10.2017 Aceito em 07.08.2020

\section{Introdução}

A competência em informação é um movimento social e científico que surgiu na década de 1970, no contexto da eclosão do paradigma da sociedade da informação. O desenvolvimento científico dessa temática, desde sua origem, está situado no campo da Ciência da Informação (CI), uma ciência essencialmente interdisciplinar que tem como o objeto central a informação sob as mais variadas manifestações. Essa ciência trata

dos problemas de efetiva comunicação de conhecimentos e de registros do conhecimento entre seres humanos, no contexto de usos e necessidades sociais, institucionais e/ou individuais de informação" (SARACEVIC, 1996, p. 2).

Os estudos sobre a competência em informação, por sua vez, estão voltados para a investigação das "habilidades, atitudes e compreensão necessárias para identificar, avaliar e usar a informação, de acordo com as necessidades de informação de cada indivíduo, em estruturas formais ou não de informação" (LEITE et al., 2016, p. 153). A congruência entre as duas esferas é evidenciada na ocasião em que se busca mutualmente compreender, descrever ou analisar situações informacionais individuais ou coletivas.

Competência em informação e CI também têm características comuns quanto à gênese: ambos os movimentos têm sua origem relacionada à sobrecarga informacional, um atributo da revolução tecnológica. A ciência e o objeto desenvolveram-se concomitantemente, e, por essa razão, as pesquisas sobre competência em informação, durante grande parte do desenvolvimento científico do movimento, sofreram 
influências teórico-epistemológicas da $\mathrm{CI}$, que a partir de sua origem transcorreram-se por um processo de expansão das fronteiras teóricas, metodológicas e epistemológicas.

Neste artigo, buscamos apresentar aspectos referentes à expansão epistemológica da CI, e a evolução teórico-metodológica dos estudos sobre competência em informação, que acompanham o desenvolvimento científico da área. Nesse sentido, apresentamos a fenomenologia enquanto corrente filosófica congruente às pesquisas sobre competência em informação: essa base epistemológica adequa-se, de modo geral, à compreensão atual do objeto da competência em informação, que contempla a construção intersubjetiva do fenômeno.

Essa discussão se dá a partir de uma pesquisa descritivoexploratória de cunho bibliográfico, com base nos procedimentos metodológicos utilizados para o embasamento teórico-conceitual. Foram utilizados, enquanto materiais úteis, os registros da literatura científica da área da Ciência da Informação e da Filosofia sobre as temáticas que circundam a investigação: Ciência da Informação, competência em informação e Fenomenologia. Foram selecionados, para compor essa construção, artigos de revistas disponíveis nos periódicos científicos nacionais e internacionais, bem como em anais de eventos e livros publicados nas respectivas áreas de investigação, publicados em qualquer período de tempo (até o ano de 2017), que abordam: a) os fundamentos teórico-epistêmico-metodológicos da Ciência da Informação e do movimento da competência em informação; b) a evolução histórica da Ciência da Informação, bem como da Competência em Informação; e c) a corrente teórico-epistemológica denominada Fenomenologia.

\section{A Expansão epistemológica do campo da ciência dainformação}

A CI tem origem na revolução técnico-científica que se seguiu à Segunda Guerra Mundial (SARACEVIC, 1996, p. 42). Naquela ocasião, observava-se a apropriação da informação e do conhecimento pela sociedade e, ainda, a transformação de ambos em forças produtivas (FREIRE, 2006, p. 10). Pelo fato de os fenômenos, os processos e as atividades de informação serem considerados elementos constitutivos centrais das atividades e das manifestações econômicas, sociais e culturais (GONZÁLEZ DE GÓMEZ, 2002, p. 30), a recuperação da informação passou a ser uma atividade substancial para o desenvolvimento: é a partir dos problemas envolvendo a recuperação da informação que a CI surgiu (LE COADIC, 1996).

O cientista Vannevar Bush, em 1945, revelou pioneiramente a problemática da sobrecarga informacional e da recuperação da informação. Em uma publicação intitulada As wemaythink, o autor 
reforçou a necessidade de tornar mais acessível o acervo crescente de informação, e, para atender tal propósito, propôs a máquina chamada MEMEX, cujo fim último consistia em recuperar a informação de modo mnemônico (SARACEVIC, 1996). Atribui-se à ideia de Bush os primeiros indícios do nascimento da CI, ainda na década de 1940 (SARACEVIC, 1996).

O destaque dado a esta apresentação é útil para reconhecermos que o berço da CI é a revolução tecnológica, e, ainda, que o problema central que permeou o surgimento desta diz respeito à necessidade de recuperar a informação para o desenvolvimento social, cultural e principalmente econômico da sociedade.

Assim, uma parte da evolução da CI esteve relacionada ao desenvolvimento de soluções que pudessem resolver tal lacuna. As investigações científicas eram essencialmente empíricas, e de natureza majoritariamente experimental (LE COADIC, 1996, p. 22-23). Durante o desenvolvimento desta ciência, é possível perceber a existência de um processo - ainda em curso - de expansão das fronteiras teóricometodológicas, e, atualmente, observamos diferentes vertentes de pesquisa, que partem de distintas visões científicas: essa diversidade expande, claramente, o escopo da CI (INGWERSEN, 1992).

A multiplicidade de visões científicas na CI é evidenciada a partir da pluralidade conceitual do objeto informação, observada na literatura científica. Nesta via, conceitos são representações simbólicas da expressão da ideia do objeto 'informação': significam construtos elaborados intencionalmente à luz de um marco teórico (RABELO, 2008, p. 25-26), e, por essa razão, expressam a postura teórica, filosófica e ideológica de uma configuração específica.

Wersig e Nevelling (1975), ainda na década de 1970, identificaram seis aproximações conceituais de informação: aproximação da estrutura, aproximação do conhecimento, aproximação da mensagem, aproximação do sentido, aproximação do efeito e aproximação do processo. A aproximação da mensagem representa uma concepção da informação enquanto um processo físico, que possibilita a transferência de um sinal de um emissor para um receptor. Estudos com base nessa concepção abordam sistemas, técnicas ou máquinas e possuem a intenção de otimizar o desempenho dos processos de transmissão de sinais. A aproximação da estrutura também parece considerar a informação como um sinal físico, porém essa visão considera o papel ativo do sujeito cognoscente, aquele que atribui sentido ao sinal. Já as orientações baseadas no conhecimento e no sentido, por sua vez, caracterizam-se pela concepção da informação enquanto um meio: na aproximação do conhecimento, a intenção é a construção do conhecimento, e na orientação do sentido, a informação é o sentido da mensagem (WERSIG; 
NEVELLING, 1975, p. 24). As outras duas aproximações - efeito e processo - apresentam uma abordagem da informação enquanto um processo: no entanto, a primeira abordagem possui foco no resultado do processo, enquanto a última atém-se para as ações do processo: a geração, a transmissão, o armazenamento e acesso (WERSIG; NEVELLING, 1975, p. 23-26).

Buckland (1991), na década de 1990, revelou três abordagens da informação: informação enquanto processo, informação enquanto conhecimento e informação enquanto coisa, que não são antagônicas, e, inclusive, podem ser complementares entre si. A primeira abordagem diz respeito ao ato de informar: a informação é, nessa concepção, a alteração do estado de conhecimento. A informação enquanto conhecimento, por sua vez, representa o resultado do processo em questão: descrito por Buckland (1991, p. 351, tradução nossa) como "a redução da incerteza". Essas duas primeiras aproximações referem-se à informação enquanto elemento intangível: não é possível, dessa forma, mensurar, gerir ou tocar (BUCKLAND, 1991, p. 351). A informação como coisa, no entanto, é indicada como um atributo tangível: pode ser representada por dados e documentos ou qualquer suporte físico, e, dessa forma, pode ser mensurada, preservando ainda sua capacidade informativa (BUCKLAND, 1991, p. 351-352).

Em que pese a ambiguidade atribuída ao termo 'informação', os conceitos e usos da informação aqui mencionados orientam as investigações científicas conduzidas na CI: há, dessa forma, correntes epistemológicas de estudo que estão ancoradas nos diferentes conceitos.

Capurro (2003) indica a existência de três paradigmas epistemológicos predominantes, que oferecem aporte teórico para pesquisas desse campo. São eles: paradigma físico, paradigma cognitivo e paradigma social. A existência desses três paradigmas evidencia o processo histórico de expansão epistemológica da CI.

Capurro (2003) salienta que a CI nasce com um paradigma físico, questionado por um enfoque cognitivo idealista e individualista, substituído posteriormente por um paradigma pragmático e social. O autor ressalta que, embora essa periodização seja útil para a ilustração do processo histórico, é necessário salientar que, ainda hoje, é possível observar a existência de investigações científicas ancoradas em transformações posteriores do paradigma físico. Não obstante, percebe-se também a existência de um paradigma social ainda na gênese da CI, que se trata de um legado da Biblioteconomia e da Documentação para esta ciência (CAPURRO, 2003).

O paradigma físico atribui à informação o objeto que um emissor transmite a um receptor. A teoria que ofereceu subsídios para a criação dessa abordagem é denominada teoria matemática da informação, e foi 
estruturada por Shannon e Weaver, em 1949. A teoria matemática considera informação a mensagem que é transmitida por um sinal físico, e, dessa forma, os aspectos semânticos e pragmáticos são desconsiderados (CAPURRO, 2003). Ao descartar a capacidade da informação de gerar significados e produzir sentido, esse paradigma também exclui o papel do sujeito cognoscente do processo informativo e comunicativo (CAPURRO, 2003).

O paradigma cognitivo, por sua vez, considera o aspecto semântico da mensagem, na medida em que se dedica à investigação dos suportes físicos do conhecimento, com o propósito de recuperar a informação. A intenção, nesse caso, é recuperar o conteúdo intelectual para preencher uma lacuna cognitiva de conhecimento. Capurro (2003) salienta que esse modelo recebe influências da teoria proposta por Belkin (1980) denominada estado anômalo de conhecimento, que considera a informação enquanto um processo de alteração de modelos mentais: o conteúdo informacional, nesse aspecto, preencheria uma lacuna de conhecimento (CAPURRO, 2003). O autor ainda destaca que os estudos cognitivos da informação tratam da investigação da forma com que os processos informativos transformam ou não o usuário. Esse sujeito, em primeiro lugar, é o "sujeito cognoscente possuidor de modelos mentais do mundo exterior, que são transformados durante o processo informacional" (CAPURRO, 2003, p. 1).

Já o paradigma social surge a partir de uma crítica ao paradigma cognitivo: Capurro (2003) salienta que as vertentes de pesquisa cognitivistas possuem uma dimensão associal ao desconsiderar os condicionamentos sociais e materiais do existir humano. Assim, a partir de teorias contemporâneas, como a fenomenologia, a hermenêutica, a semiótica e a teoria crítica, o paradigma social forma-se para atribuir ao sujeito um papel ativo no processo de construção do conhecimento. Esse sujeito é possuidor de uma historicidade social, influencia e recebe influências do meio social. É integrado ao mundo exterior (CAPURRO, 2003).

Capurro (2003), com base em Luhmann (1987), ressalta que no paradigma social há uma diferenciação entre a mensagem, ou oferta de sentido, e a própria informação, que é a seleção de sentido. O sujeito é um ser dotado de uma pré-compreensão, a seleção do sentido e, desse modo, este mesmo sujeito é resultado de um processo de interpretação e internalização da mensagem, a partir de um julgamento sobre a validade do conteúdo para o sistema de conhecimentos deste ou do grupo social ao qual pertence (CAPURRO, 2003). O paradigma social é evidenciado, nessa concepção, na ocasião em que a pré-compreensão não é entendida como um estado de compreensão de um sujeito ou usuário isolado, mas, por outro lado, a pré-compreensão "de determinada comunidade assim como 
a de um campo específico de conhecimento e/ou de ação no qual o usuário já está implícita ou explicitamente inserido (CAPURRO, 2003).

Araújo (2003) também concebe uma vertente social nos estudos desenvolvidos na $\mathrm{CI}$. O autor destaca que essa vertente legitima esta ciência enquanto uma ciência social. Ainda, afirma que a CI só se efetivou enquanto uma ciência social na ocasião em que passou a incorporar conceitos oriundos de correntes interpretativas e microssociológicas, como, por exemplo, o construtivismo social de Berger e Luckmann e a fenomenologia social de Alfred Schutz (ARAÚJO, 2003). Essas teorias incluem, nos estudos sobre a informação, a integração natural dos sujeitos com o meio social, isto é, as interações cotidianas, as formas de expressão e linguagem, os ritos e processos sociais como parte dos sistemas de informação (ARAÚJO, 2003, p. 24-25).

Ao reconhecer o papel ativo do sujeito nos processos de informação - um ser "complexo, contraditório, inacabado e, em permanente transformação" (MINAYO, 2010, p. 22) - e, ainda, o resultado da interação entre o self e o meio social, esse paradigma social admite a subjetividade dos processos informacionais, ou melhor, a intersubjetividade, em que a realidade é construída a partir das infinitas interações cotidianas (ARAÚJO, 2003).

Araújo (2003) também menciona a existência de vertente epistemológicas que determinam a condução de pesquisas em CI enquanto uma ciência social. O autor afirma que existem três correntes de pesquisa: além da corrente social, que utiliza bases filosóficas interpretativas e microssociológicas, há, ainda, a corrente positivista/funcionalista, que tem base na sociologia funcionalista de Augusto Comte e Emile Durkhein, e a corrente crítica, que se apropria de conceitos e bases teóricas marxistas e pós-marxistas.

A corrente positivista/funcionalista está presente no início da CI, segundo Araújo (2003). Empresta-se de conceitos sociológicos funcionalistas, e observa a sociedade enquanto estrutura composta por partes (indivíduos) que desempenham funções para o funcionamento da estrutura social. Nesse período, Araújo (2003) afirma que os estudos em CI observavam a realidade social a partir de uma perspectiva estatística, quantitativa. Dentre os estudos envolvendo essa abordagem, o autor ressalta as investigações que utilizam sociogramas para mapeamento dos fluxos de informação, além da aplicação de questionários a grandes amostras de usuários (ARAúJO, 2003, p. 24).

A corrente crítica, por sua vez, observa a realidade social a partir da perspectiva do conflito. Araújo (2003) ressalta que a teoria crítica na ciência da informação possui, basicamente, três elementos: 1) a historicidade como condição para a explicação dos fenômenos, 2) o conflito, e 3) a inserção de todo fato isolado no contexto global de 
relações de luta por poder. Dessa forma, investigações críticas na CI enfocam o desequilíbrio nos fluxos e no acesso à informação, as distribuições desiguais de poder no ambiente da informação, e o caráter da informação enquanto elemento tanto de dominação quanto de resistência. Exemplos dessas investigações podem incluir estudos envolvendo informação e cidadania, ação cultural, exclusão informacional, democratização da informação (ARAÚJO, 2003, p. 25). Os estudos críticos da informação partem da concepção de que a informação é um "elo de ligação entre um produto de reflexão e um processo de reflexão, estando, pois, intimamente relacionado com o processo de construção do conhecimento e por esta via tornando-se um instituinte cultural, gerador de mudanças ou reprodutor do estabelecido" (CARDOSO, 1994, p. 110111).

Assim, reconhecemos que a CI hoje concebe as investigações científicas a partir de três paradigmas, segundo Capurro (2003): o físico, o cognitivo e o social. Por outro lado, Araújo (2003) sustenta três correntes epistemológicas que embasam os estudos do campo: positivista/funcionalista, crítica e social.

É possível observar algumas interlocuções entre os paradigmas designados por Capurro (2003) e as correntes epistemológicas - oriundas da sociologia - indicadas por Araújo (2003). Devemos reconhecer, no entanto, que o paradigma físico não apresenta relações epistemológicas com as vertentes mencionadas por Araújo (2003): esse paradigma consistiu-se a partir de conceitos originados nas ciências exatas, notadamente a teoria matemática da informação, e, pelo fato de desconsiderar aspectos humanos (semânticos e pragmáticos) nos processos de informação e comunicação (CAPURRO, 2003), não estabelece uma relação com a CI enquanto ciência social.

Nesta linha de raciocínio, identifica-se a existência uma aproximação epistemológica entre o paradigma cognitivo (CAPURRO, 2003) e a corrente positivista/funcionalista (ARAÚJO, 2003). Essa aproximação é evidenciada na ocasião em que ambos os modelos assumem que o sujeito cognoscente exerce papel ativo no processo de construção do conhecimento. No entanto, tais vertentes desconsideram os condicionamentos sociais enquanto elementos de interferência nesse processo: a ideia dos estados anômalos de conhecimento (BELKIN, 1980), por exemplo, que oferece base para o paradigma cognitivo mencionado por Capurro (2003), concebe esses estados como 'lacunas' cognitivas dos sujeitos "que seriam preenchidas com 'coisas' chamadas informação, encontradas nos sistemas e serviços de informação" (ARAúfo, 2009, p. 201). Assim, o paradigma cognitivo possui uma raiz funcionalista, ao conceber a informação como algo independente dos sujeitos e dos contextos histórico-culturais, o que a torna passível de ser estudada 
objetivamente, medida, e ser compreendida por meio de leis e regularidades (ARAÚJO, 2009, p. 200).

O paradigma social de Capurro (2003) e a corrente social de Araújo (2003), por sua vez, parecem ter sólidas interlocuções epistemológicas. Ambas vertentes consideram que os sujeitos são, naturalmente, envolvidos socialmente em uma rede de relações e significados (CAPURRO, 2003). A informação, nesse caso, é percebida como um processo "percebido e compreendido de variadas formas de acordo com os sujeitos que estão em relação" (ARAúJO, 2003, p. 25).

Ainda, enquanto Araújo (2003) identifica uma corrente crítica da informação, Capurro (2003) concebe a perspectiva crítica como elemento do paradigma social. Este autor menciona, que, embora algumas teorias decorrentes das vertentes crítica e social possuam divergências - que podem incluir aspectos relacionados à observância do espaço social ambas manifestam "o caráter fundamentalmente interpretativo do conhecimento" (CAPURRO, 2003).

Dessa forma, a CI enquanto ciência social abarca os paradigmas cognitivo, que se aproxima daquele funcionalista e positivista mencionado por Araújo (2003), social, e, ainda, uma corrente crítica, que, embora exprima uma abordagem interpretativa/social, enfatiza o conflito, a distribuição desigual de poder e de recursos, a informação enquanto elemento de dominação, entre outros. As pesquisas sobre competência em informação, enquanto investigações situadas no campo da CI, seguem essa trajetória. Na próxima seção, é possível observar os aspectos referentes à trajetória teórico-epistemológica das pesquisas sobre competência em informação no decorrer do desenvolvimento científico do movimento.

\section{Epistemologia das pesquisas sobre competência em informação}

Competência em informação é aqui compreendida como o conjunto de habilidades, conhecimentos e atitudes relacionados à busca, acesso, avaliação, comunicação e uso da informação de forma eficiente e criativa (DUDZIAK, 2003; AMERICAN LIBRARY ASSOCIATION, 1989). Trata-se de um movimento científico marcado por uma pluralidade de vertentes de pesquisa. Nessa seção, discorremos acerca dessa pluralidade, que está, parcialmente, em consonância com a evolução teórico-epistemológica da CI.

O movimento da competência em informação - originalmente informationliteracy, no inglês - foi citado pela primeira vez no documento The informationserviceenvironment: relationshipsandpriorities, elaborado pelo bibliotecário americano Paul Zurkowski (1974). O autor relatou, naquela ocasião, que se experimentava uma superabundância de 
informação que excedia a capacidade de avaliá-la, e mencionou a competência em informação como o conjunto de técnicas e habilidades para utilizar a vasta gama de recursos de informação na solução de problemas informacionais. A competência em informação, para o autor, envolve, além da capacidade de ler e de escrever, o reconhecimento do valor da informação e a habilidade de ajustar a informação para atender a necessidades (ZURKOWSKI, 1974, p. 6). Ainda, define informação como o conjunto de

conceitos e ideias que entram no campo de percepção de um indivíduo, são avaliadas e assimiladas, e fortalecem ou mudam o conceito de realidade desse sujeito, e/ou sua capacidade de agir. (ZURKOWSKI, 1974, p. 1, tradução nossa).

As características levantadas por Zurkowski (1974) revelam uma associação da disciplina científica de competência em informação à ciência da informação enquanto uma ciência social, a qual tem por característica principal a investigação da natureza social dos fenômenos informacionais (ARAÚJO, 2003). Essa aproximação é evidenciada na ocasião em que o princípio fundamental da competência em informação, levantado por Zurkowski (1974), diz respeito à utilização da informação para a solução de problemas informacionais. Essa utilização, envolve a habilidade de adequar a informação para atender as necessidades: um processo essencialmente social, ao expressar-se na interação/mediação do indivíduo com o meio.

Ainda, é possível reconhecer que a gênese da competência em informação está ancorada no paradigma cognitivo da CI, que atribui à informação a característica de possuir capacidade de modificar um estado de conhecimento. Os elementos mencionados por Zurkowski (1974) que evidenciam uma aproximação à epistemologia cognitivista são: 1) atribuição de cognoscibilidade ao ser, que identifica seu estado anômalo; e, 2) concepção do sujeito enquanto um ser dotado de uma "capacidade de agir" (ZURKOWSKI, 1974, p. 1, tradução nossa), ou seja, um ser capaz de reunir recursos - nesse caso, de informação - para solucionar uma situação, ou reparar tal estado anômalo.

Parte da construção teórica e epistemológica da competência em informação é oriunda de contribuições de investigações de natureza cognitivista. No entanto, podemos reconhecer nos estudos dessa natureza a condução de diferentes abordagens de pesquisa, as quais podem indicar vertentes distintas do paradigma cognitivo.

Algumas investigações, por exemplo, procuram compreender elementos da competência em informação a partir de uma perspectiva estatística, quantitativa, o que denota a presença de aspectos de pesquisa 
positivistas e funcionalistas. David Bawden (2001), por exemplo, afirma que algumas pesquisas de movimentos adjuntos da competência em informação (para o autor, subconjuntos), notadamente os movimentos denominados computer literacy ou information technology literacy, investigam aspectos da competência em informação a partir da mensuração de tarefas básicas concluídas pelos indivíduos, no computador. Essas vertentes partem da premissa de que o indivíduo letrado - sob a perspectiva da tecnologia e da informática - é aquele que consegue completar atividades básicas em um computador, como processar palavras ou criar e manipular dados em planilhas e softwares (BAWDEN, 2001). Esses estudos parecem adequar-se ao que Boon, Johnston e Webber (2007, p. 214) chamam de concepção simplista da competência em informação, que parte da premissa de que o indivíduo letrado é aquele que pode acessar e recuperar informação de forma fácil e rápida. Estudos dessa abordagem - que podem estar presentes não só nas investigações envolvendo computer literacy, mas também de library literacy e também information literacy de um modo geral - direcionam o sentido da competência em informação para a perspectiva do acesso e recuperação da informação, estando ainda ancorados num paradigma cognitivo.

Na verdade, Bawden (2001) ressalta que a palavra letramento - ou, para o inglês, literacy, que oferece o conteúdo semântico para a expressão information literacy, diz respeito, de uma forma simples, à utilização eficaz da decodificação e reprodução da palavra escrita. Essa concepção identifica um indivíduo letrado como aquele capaz de utilizar, com eficácia, a linguagem escrita, ou seja, aquele que pode ler e escrever. Assim, podemos perceber que o próprio conceito de letramento exclui, do processo de desenvolvimento dessa capacidade, a posição crítica e reflexiva do sujeito que apreende o conteúdo, que está relacionada ao sujeito e seu meio de atuação social. Dessa forma, a etimologia da expressão já denotaria uma aproximação do movimento à vertente positivista/funcionalista, ao desconsiderar condicionamentos sociais revelados no sujeito - como elementos dinâmicos que interferem nos processos informacionais.

No entanto, Bawden (2001) também destaca que existe outra concepção de letramento, mais aprofundada. Essa concepção, idealizada por Gilster (1997 apud BAWDEN, 2001) envolve algo além da simples habilidade de ler e escrever: significa a capacidade de ler com sentido, e compreender. Assim, envolve "o estado de ser capaz de ler e compreender informação básica, como a habilidade de entender quantas cápsulas deve-se ingerir em um dia, a partir das instruções impressas nos medicamentos" (BAWDEN, 2001, p. 220-221, tradução nossa). Gasque (2012) corrobora com a concepção de letramento de Bawden (2001): a 
autora ainda ressalta que há, na literatura, concepções errôneas da palavra, que, inclusive, coincidem com a noção de alfabetização. Para Gasque (2012), alfabetização e letramento representam processos diferentes: a alfabetização vincula-se ao domínio básico do código da língua, enquanto o letramento transcende a decodificação para situações em que há o uso efetivo da língua nas práticas de interação, em um contexto específico. Dessa forma, este representa um processo complexo, e, aplicado ao contexto da informação, possui "como finalidade a adaptação e a socialização dos indivíduos na sociedade da aprendizagem" (GASQUE, 2012, p. 32).

Sob concepções mais elaboradas de letramento, podemos reconhecer um amplo movimento de pesquisas - ainda de natureza cognitivista - que participaram da construção teórica da competência em informação. Essas concepções distanciam-se do enfoque relacionado ao acesso à informação, aproximando-se de uma perspectiva voltada para a aplicação da informação nas situações 'mal resolvidas'. Tratam-se, dessa forma, de uma abordagem voltada para as necessidades de informação e para a aplicação da informação para preencher lacunas.

Documentos amplamente citados na literatura que constituíram-se como elementos norteadores para a trajetória do movimento possuem, em seu cerne, orientação para a abordagem das necessidades de informação: o documento elaborado pela American Library Association (ALA) denominado Presidential Commiitte on Information Literacy: Final Report (1989), por exemplo, identifica o indivíduo competente em informação como aquele capaz de encontrar, avaliar e utilizar a informação eficazmente na solução de problemas e na tomada de decisão. Tal abordagem direciona o foco do movimento para a situação que demanda a informação (um problema ou uma tomada de decisão), ou seja, para a necessidade de informação, sendo essa, naturalmente, uma necessidade derivada, que é advinda de uma situação do dia-a-dia (LE COADIC, 1996). Outro fragmento do documento, que define competência em informação como um conjunto de habilidades informacionais que são desenvolvidas "para atender a uma ampla variedade de necessidades pessoais e de negócios" (AMERICAN LIBRARY ASSOCIATION, 1989), evidencia a centralização do processo para a perspectiva das necessidades de informação.

O documento elaborado pela mesma instituição, denominado Information Literacy Competency Standards for Higher Education define competência em informação como a capacidade de "reconhecer quando a informação é necessária [...] e utilizar efetivamente a informação demandada" (AMERICAN LIBRARY ASSOCIATION, 1999, tradução nossa), o que evidencia o direcionamento para as necessidades de informação. 
Nos documentos apresentados, a percepção da competência em informação enquanto capacidade de mobilizar recursos para atender a uma situação mal resolvida de informação, denominada necessidade de informação, é o que se destaca. Essa abordagem - que deu sustentação para uma gama de pesquisas que contribuíam para a solidificação do movimento científico - volta-se para a noção de competência, em detrimento da noção de letramento. A noção de competência, por sua vez, contempla a "aptidão para enfrentar um conjunto de situações análogas, mobilizando, de forma correta, rápida, pertinente e criativa, múltiplos recursos cognitivos: saberes, capacidades, microcompetências, informações, valores, atitudes [...]" (PERRENOUD et al., 2002, p. 19).

Nessa perspectiva, a abordagem das necessidades volta-se para os papéis do indivíduo na vida social. O relatório de uma reunião do National Forum on Information Literacy, uma comissão formada na década de 1990 para "desenvolver e disseminar o entendimento da importância crítica do conceito" (DOYLE, 1992, p. 2), deu ênfase para a atuação dos indivíduos nos diversos contextos que a vida social apresenta, incluindo a competência em informação como uma estratégia de desenvolvimento de "aprendentes ao longo da vida, cidadãos responsáveis e trabalhadores com habilidades empregáveis" (DOYLE, 1992, p. 6, tradução nossa).

Emergem, nesse período, alguns elementos funcionais à competência em informação que são intrínsecos - mas não exclusivos - ao paradigma cognitivo. São eles: 1) aproximação ao movimento do aprendizado ao longo da vida - um movimento educacional que estimula a aprendizagem fora dos ambientes tradicionais (escola, universidade, etc.) e se estende por todos os períodos da vida de um sujeito, possibilitando o desenvolvimento da autonomia e da flexibilidade (DUNNE, 2013, p. 6); e 2) orientação para a formação de profissionais competentes para a atuação no mundo do trabalho e na esfera social.

Esses dois conceitos, na visão de Kapitzke (2003), estão interrelacionados. O autor afirma que a variação semântica da competência em informação voltada para as "atitudes e habilidades que estão na mente" (KAPITZKE, 2003, p. 6, tradução nossa), que se aproxima da abordagem por nós denominada cognitivista, está ancorada na nova lógica capitalista, a qual requer dos trabalhadores novas formas de aprendizagem e de trabalho. Essas novas formas privilegiam a velocidade, flexibilidade $e$ inovação. A expertise, nessa nova lógica, "não é vista como um produto, mas um processo fluido" (KAPITZKE, 2003, p. 8, tradução nossa). É nesse sentido que a aprendizagem ao longo da vida parece fazer sentido, ao estimular a autonomia, a flexibilidade, e, consequentemente, a inovação.

É possível reconhecer diversas abordagens de pesquisa cognitivistas que possuem foco na competência. Destacamos, dentre elas, aquelas conduzidas a partir da teoria dos estados anômalos do conhecimento, que 
foi proposta por Belkin (1980), e foca-se para a recuperação da informação para a "redução de incerteza", a qual se origina numa "situação problemática", reconhecida pelo indivíduo quando este percebe que Ihe falta informação para resolver um problema (BELKIN, 1980, p. 137, tradução nossa).

É possível também identificar uma vertente de pesquisas da competência em informação próxima ao paradigma social da CI, exposto por Araújo (2003). Esta originou-se a partir de um movimento maior que contemplou a CI como um todo, denominado "movimento de alargamento das fronteiras da ciência da informação" (GANDRA; DUARTE, 2012). Essa coalizão, segundo Marciano (2006, p. 183), possibilitou a emergência de novas abordagens para o campo, voltadas para os aspectos humanistas e sociais dos problemas relacionados à informação. Gandra e Duarte (2012) expressam que, a partir desta visão, abre-se uma nova agenda de pesquisas na área, que direciona o foco para a construção de significados por parte do sujeito, em vez de investigar taxas de uso de fontes de informação, ou estimativas quantitativas: "esta nova agenda busca enxergar as ações dos usuários dotadas de significados para eles mesmos" (GANDRA; DUARTE, 2012, p. 14).

No movimento da competência em informação, essa nova agenda preconiza a informação enquanto um objeto de valor (ASSOCIATION OF COLLEGE AND RESEARCH LIBRARIES, 2016). Nesse aspecto, a informação é concebida como um insumo, como um meio de educação, como um meio de influência e como um meio de entender o mundo (ASSOCIATION OF COLLEGE AND RESEARCH LIBRARIES, 2016). Assim, compreende-se que há "interesses jurídicos e socioeconômicos influenciam a produção e distribuição da informação" (ASSOCIATION OF COLLEGE AND RESEARCH LIBRARIES, 2016, p. 6, tradução nossa). A partir desse contexto, esse paradigma implica uma postura crítica e reflexiva sobre a validade da informação. Admite-se, enquanto elementos da competência em informação, as habilidades (relacionadas ao acesso), conhecimentos (relacionados à avaliação), atitudes (relacionados à aplicação da informação no dia-a-dia), e, ainda, já a incorporação de, a agregação de valores relacionados com a utilização da informação: inclui-se, na discussão da competência em informação, "a ética, a autonomia, a responsabilidade, a criatividade, o pensamento crítico e o aprender a aprender, enfatizando o cidadão, o ser social, admitindo uma visão sistêmica da realidade" (DUDZIAK, 2001, p. 152).

A informação, no paradigma social, é reconhecida como uma estrutura essencial à incorporação de valores no sistema social, e, por essa razão, é determinada como uma função necessária à manutenção das sociedades democráticas (OWENS, 1976 apud DUDZIAK, 2003). Ao ser considerada como um atributo fundamental para a cidadania, a 
competência em informação, é, então, uma necessidade prática e um direito moral (LENOX; WALKER, 1994).

O amadurecimento teórico-epistêmico-metodológico do movimento, evidenciado na eclosão dessas novas concepções de competência em informação, influenciou, inclusive, na tradução do termo information literacy para o Brasil. Trata-se de um fenômeno natural: no documento Overview of Information Literacy Resources Worldwide, produzido por Horton Junior (2013) para a UNESCO, salienta-se que a tradução em cada idioma e em cada país está associada à construção teórico-epistemometodológica da disciplina em cada região específica; podendo, então, a disciplina seguir um rumo diferente, a depender de variáveis como: orientação teórico-epistemológica dos pesquisadores da temática do país, desenvolvimento do campo no local, e, inclusive, pode se sujeitar às manifestações culturais de cada região.

Embora não possuamos, nesta discussão, adentrar no debate terminológico, devemos salientar que, no Brasil, os primeiros estudos da temática, desenvolvidos por Caregnato (2000) e Dudziak, Gabriel e Villela (2000), adotaram a expressão 'alfabetização informacional' para designar information literacy. Já Dudziak (2003), a partir de uma investigação aprofundada sobre concepções da information literacy, sugeriu a adoção do termo competência em informação para o português, a qual definiu como o conjunto de habilidades, conhecimentos, atitudes e valores relacionados à informação. No mesmo ano, Campello (2003) adotou a expressão Competência Informacional, justificando a escolha ao mencionar que a palavra competência seria capaz de "englobar as diversas gamas de literacy que surgiram na última década" (CAMPELLO, 2003), notadamente se referindo às novas concepções e interpretações referentes à temática.

Atualmente, a expressão mais adotada no Brasil é competência em informação: Santos (2017) argumenta que, embora outras denominações - como letramento informacional e alfabetização informacional compreendam outras formas de visualizar o movimento, a expressão competência em informação possui maior aceitação em virtude de sua semântica ser direcionada ao domínio do recurso 'informação', além de o termo ser expresso para legitimar a fundação do movimento no campo da Ciência da Informação (SANTOS, 2017, p. 58).

O paradigma social da competência em informação evidencia-se em pesquisas de natureza interpretativa, como, por exemplo, aquelas que se associam às correntes subjetivistas e fenomenológicas. Dentre as investigações conduzidas sob essa vertente, podemos destacar aquelas que utilizam o método fenomenográfico (ANDRETTA, 2007; BOON; JOHNSTON; WEBBER, 2007; JOHNSTON; PARTRIDGE; HUGHES, 2014), as quais consideram a competência em informação um 'fenômeno' subjetivo, 
que pode ter diferentes significados de acordo com os contextos, e buscam obter uma "compreensão mais profunda e complexa das realidades subjetivas nos diversos aspectos do usuário da informação no 'mundo vivido'"' (FORSTER, 2015, p. 353, tradução nossa).

Há, ainda, uma abordagem crítica da competência em informação, revelada no movimento denominado Critical Information Literacy, que também já é explorado no Brasil sob a expressão 'competência crítica em informação' (DOYLE; BEZERRA, 2016; FIGUEIREDO, 2016; BEZERRA; SCHNEIDER; BRISOLA, 2017). Esse movimento origina-se numa crítica aos modelos predominantes da competência em informação, denominados por Elmborg (2012) como modelos autônomos. Parte-se, nesse modelo, de uma crítica aos processos informacionais constituintes do fluxo da competência em informação, os quais envolvem o reconhecimento das necessidades, a busca, o acesso e o uso da informação. Tratam-se, segundo Elmborg (2012), de processos estáticos, que perpetuam uma cultura - capitalista - dominante, desconsiderando o caráter dinâmico do movimento. A teoria criticada pelo autor concebe, então, o sujeito como um mero apreensor de uma 'coisa' que é a competência em informação, desconsiderando seu papel ativo e crítico na construção dos seus próprios processos informacionais. O reconhecimento das necessidades de informação, por exemplo, é considerado por Elmborg (2012) como um processo mecânico, sem significado, e as atividades que envolvem o acesso aos recursos de forma 'efetiva e eficiente' vão de encontro ao processo natural de construção de conhecimento do indivíduo, que é lento e minucioso. Ainda, o autor salienta que a avaliação da informação envolve, em teoria, um julgamento de valor sobre o que é 'má' informação e o que é 'boa' informação, sendo este julgamento já delimitado por um padrão, que foi criado a partir critérios de julgamento de informação definidos por um corpo social de características históricas e sociais possivelmente distintas daquele sujeito que tenta construir sua competência em informação (ELMBORG, 2012, p. 93). Então, na teoria crítica da competência em informação, percebe-se o movimento tradicional como algo que se desenvolve em função de uma missão capitalista de "maximizar a produtividade e criar força de trabalho competitiva no século vinte e um" (ELMBORG, 2012, p. 87, tradução nossa), e impõe o discurso de uma cultura capitalista dominante (TEWELL, 2015, p. 26).

Essa teoria está também realiza críticas aos modelos pedagógicos tradicionais, os quais cumprem o propósito de "criar trabalhadores eficientes" (TEWELL, 2015, p. 25, tradução nossa). O movimento da aprendizagem ao longo da vida, que preconiza a formação de sujeitos autônomos e independentes, está, ainda segundo o movimento em voga, redirecionando o foco da aprendizagem: de "learning to be" (aprender 
para ser, em inglês) para "learning to be productive" (aprender para ser produtivo, em inglês) (BIESTA, 2012, p. 8, tradução nossa).

A competência crítica em informação, então, empresta elementos da teoria crítica da pedagogia, notadamente a teoria de Paulo Freire (ELMBORG, 2012; GREGORY; RIGGINS, 2013; TEWELL, 2015) para preconizar uma competência em informação que estimule a consciência e o pensamento crítico, compreendendo o indivíduo além de um repositório de informação, ou um consumidor numa pista de pouso aguardando uma posição confortável num cenário altamente competitivo e perverso (TEWELL, 2015, p. 93). Assim, a proposta do modelo crítico busca "questionar e resistir aos efeitos danosos da educação centrada no capital" (TEWELL, 2015, p. 26, tradução nossa), na medida em que estimula os indivíduos a empoderar-se para, então, serem capazes de identificar e agir sobre as estruturas opressivas de poder (TEWELL, 2015, p. 36). A partir dessa nova proposta, será possível, então, idear "uma sociedade mais independente, mais participativa, que não seja objeto de outras sociedades nem de uma ínfima parte de si mesma" (BEZERRA; SCHNEIDER; BRISOLA, 2017, p. 14).

Assim, os estudos críticos da informação enfatizam os diferentes papéis dos agentes na estrutura social, as assimetrias na acumulação de capital cultural e as desigualdades presentes no acesso à informação (BEZERRA; SCHNEIDER; BRISOLA, 2017, p. 13). Ainda, as investigações sob esse prisma direcionam o foco para os grupos que estão em posição desfavorável na relação assimétrica de poder, que, na sociedade atual, são denominados grupos oprimidos, excluídos, minorias sociais ou grupos em condição de vulnerabilidade social.

Diante destas evidências, argumentamos que compreendemos a competência em informação a partir de uma perspectiva social: trata-se de um movimento intersubjetivo, que se manifesta a partir da relação do sujeito com o fenômeno e com os demais atores sociais (meio). A fenomenologia, uma corrente teórica que preconiza a intersubjetividade enquanto elemento basilar para o desenvolvimento das experiências em competência em informação, é concebida nesse trabalho como a orientação epistemológico-metodológica congruente às pesquisas sobre a temática.

\section{A abordagem fenomenológica enquanto aporte teórico- metodológico congruente às pesquisas em competência em informação}

Anteriormente, ressaltamos que o positivismo e as teorias sociológicas funcionalistas estão fundamentados em parte das pesquisas 
em $\mathrm{CI}$, e estavam em voga durante o primeiro período de desenvolvimento da ciência. Na verdade, a própria ciência de um modo geral sustentou-se, durante algum tempo, a partir de um paradigma positivista, uma doutrina objetivista que, na relação epistemológica entre sujeito e objeto, coloca este último elemento no centro da gravidade da produção de conhecimento (HESSEN, 2012). Essa posição filosófica da teoria do conhecimento pareceu, em princípio, fornecer a validade que o método científico de construção do conhecimento necessitou para consolidar-se. Nas teorias positivistas, a proposta do método científico consiste em construir verdades absolutas e universais: qualquer elemento variável ou subjetivo invalida um conhecimento enquanto científico.

A evolução da Filosofia da Ciência e da Teoria do Conhecimento possibilitou o desenvolvimento de novas correntes filosóficas, notadamente as teorias subjetivistas. As vertentes subjetivistas - que surgiram a partir de Husserl (1996) - colocam o sujeito no centro da relação epistemológica entre o sujeito e o objeto. Assim, a verdade é limitada em sua validade: depende do julgamento do sujeito cognoscente. Sendo o sujeito cognoscente um ser em permanente transformação (MINAYO, 2010), a verdade é, então, relativa, e não absoluta nem universal (HUSSERL, 1996).

A origem etimológica da fenomenologia remete à palavra fenômeno, que é oriunda da palavra grega fainomenon, designada como aquilo que se mostra, ou que se manifesta, ou, ainda, aquilo que aparece. É, para Bicudo (1994, p. 17), "o que se manifesta para uma consciência", ou, para Martins, Boemer e Ferraz (1990), aquilo que se revela para o sujeito que interroga. A fenomenologia, então, compreende a descrição desses fenômenos conforme eles se manifestam na consciência do sujeito (MARTINS; BOEMER; FERRAZ, 1990).

A proposta da fenomenologia enquanto ciência e enquanto metodologia é descrever as essências da consciência e de seus atos, segundo Husserl (MARTINS; BOEMER; FERRAZ, 1990). A busca da essência seria o 'retorno às coisas mesmas', ou seja, a percepção da consciência com relação ao objeto (GIDDENS, 1996). Essa essência, descrita como percepção da consciência com relação ao objeto, manifestase nas vivências, ou melhor, em cada vivência particular revelada pelo sujeito em cada interação sua com o objeto (DARTIGUES, 2013).

Vivências são, para a fenomenologia, ocorrências particulares. São interações da consciência em relação ao mundo, sendo esse um simples fenômeno, e não uma existência exterior ao sujeito (DARTIGUES, 2013). O mundo, pois, só tem "sentido em sua manifestação na vivência" (DARTIGUES, 2013, p. 22). As vivências, dessa forma, estão estreitamente vinculadas ao fenômeno experimentado. 
Esta é a proposta de investigação fenomenológica: descrever "as vivências intencionais da consciência para perceber como aí se produz o sentido dos fenômenos, o sentido desse fenômeno global que se chama mundo" (DARTIGUES, 2013, p. 22). Sendo as vivências intencionais resultado de uma experiência explorada pelo sujeito em relação ao objeto, a fenomenologia, então, busca "discernir e descrever a estrutura essencial da experiência" (CERBONE, 2012, p. 27). Experiência revela-se, para Cerbone (2012), na apreensão dos fenômenos pela consciência.

Os fenômenos - que são captados pela consciência - são resultado do mundo vivido. Esse mundo vivido, segundo Husserl (1996), diz respeito ao mundo natural e ao mundo dos outros: é, assim, intersubjetivo, um resultado sintético do mundo privado dos seres, cada qual com suas experiências, seus fenômenos e suas unidades fenomênicas (HUSSERL, 1996, p. 151-152). Husserl ainda atribui ao 'outro' a legitimidade da experiência vivida:

No campo originário da atividade humana [...] lidamos com seres e situações valoramente apreendidos. Diferentes perspectivas de valores visam o mundo de múltiplas maneiras, cada uma com a pretensão de verdade, que, para confirmar sua universalidade, exige o seu reconhecimento pelas demais, configurando assim uma estrutura intersubjetiva sempre em busca do consenso (FERRAZ, 2004, p. 370-371).

Dessa forma, a fenomenologia busca a experienciação do fenômeno (objeto) pelo sujeito a partir da sua consciência, compartilhada com os demais atores sociais.

Alguns elementos nos levam a argumentar em prol da vertente social como vertente congruente aos estudos da temática, bem como a fenomenologia como um aporte teórico-metodológico compatível à tais investigações. Partimos, inicialmente, da concepção de que o elemento estruturante da competência em informação - a informação - é um elemento político, produzido pelo ser humano para atender a uma necessidade também humana (PINHEIRO, 1998), de caráter social (WERSIG; NEVELING, 1975). Tal concepção de um caráter essencialmente social da informação e sua natureza política - a qual admite a existência de interesses jurídicos e socioeconômicos que influenciam a produção e distribuição da informação (ASSOCIATION OF COLLEGE AND RESEARCH LIBRARIES, 2016, p. 6, tradução nossa) fundamentam, dessa forma, investigações sobre competência em informação a partir de uma perspectiva social. De igual maneira, ao compreendermos a competência em informação como um processo que se dá no ser humano, e que o ser 
humano é naturalmente "complexo, contraditório, inacabado e, em permanente transformação" (MINAYO, 2010, p. 22), conforme mencionado anteriormente, é indubitável, ainda, compreender que a subjetividade é um componente inerente ao processo.

Ainda nesse aspecto, ao compreendermos o objeto central da competência em informação como um elemento inserido num contexto histórico e sociocultural (PINHEIRO, 2004), resultado das "práticas e representações de sujeitos vivendo e interagindo na sociedade, e inseridos em determinados espaços e contextos culturais" (MARTELETTO, 2002, p. 102), e, ao compreendermos que a competência em informação revela-se na vida em sociedade e no compartilhamento com os demais atores sociais (DE LUCCA; VITORINO, 2015), assumimos, naturalmente, que o movimento é intersubjetivo.

A intersubjetividade da competência em informação também pode ser manifestada na ocasião em que concebemos o conhecimento como um processo legitimado no marco de um grupo social: observado a partir do viés da intersubjetividade, o conhecimento só é reconhecido como 'informativo' se o observarmos "em relação a um pressuposto conhecido e compartilhado com outros, com respeito ao qual a informação pode ter o caráter de ser nova e relevante para um grupo ou para um indivíduo" (CAPURRO, 2003, p. 1).

Também, na medida em que compreendemos o conhecimento "como um fluxo de acontecimentos, isto é, uma sucessão de eventos, que se realizam fora do estoque, na mente de algum ser pensante e em determinado espaço social" (BARRETO, 2002, p. 68), admitimos que a formação de conhecimentos - missão da competência em informação está intrinsicamente relacionada às vivências e experiências. A descrição da estrutura essencial das experiências com relação à informação e ao conhecimento - método preconizado pela fenomenologia - configura-se, assim, como procedimento capaz de revelar as manifestações da competência em informação nas pessoas, nesse aspecto.

\section{Considerações Finais}

A partir da compreensão dos elementos aqui expostos, podemos observar, primeiramente, a existência de três paradigmas da CI que evidenciam a expansão epistemológica do campo. São eles: paradigma físico, paradigma cognitivo e paradigma social. A competência em informação é um movimento que surgiu na ocasião em que a CI já apresentava relação com as ciências sociais, e, dessa forma, revela-se a partir de três correntes epistemológicas: corrente cognitiva, com aproximações funcionalistas e positivistas, corrente social e corrente crítica, as quais orientam as investigações que atualmente são desenvolvidas na temática. Ainda, no paradigma cognitivo, podemos 
compreender duas vertentes: a vertente voltada às necessidades de informação; e a vertente direcionada ao acesso à informação e o desenvolvimento de habilidades relacionadas ao manejo técnico dos recursos de informação. Há, ainda, de se compreender que o paradigma social e o paradigma cognitivo não são excludentes entre si: ambos manifestam "o caráter fundamentalmente interpretativo do conhecimento" (CAPURRO, 2003).

Por fim, os argumentos levantados neste texto subsidiam a constatação de que a intersubjetividade é um componente fundamental para a investigação da competência em informação, e que a descrição das experiências configura-se como método adequado para compreender as manifestações desse processo. A fenomenologia, enquanto corrente epistemológica intersubjetiva, que considera o mundo vivido como o resultado da experiência natural em associação à experiência com os demais atores sociais, constitui-se, dessa forma, como um terreno fecundo para a exploração do movimento da competência em informação no contexto atual.

\section{Referências}

AMERICAN LIBRARY ASSOCIATION. Presidential Committee on Information Literacy: final report. Washington, 1989.

AMERICAN LIBRARY ASSOCIATION. Information Literacy Competency Standards for Higher Education. Association of College and Research Libraries: 1999.

ANDRETTA, S. Phenomenography: a conceptual framework for information literacy education. As lib Proceedings, v. 59, n. 2, p. 152-168, 2007.

ARAúJO, C. A. A. A ciência da informação como ciência social. Ciência da Informação, Brasília, v. 32, n. 3, p. 21-27, set./dez. 2003.

ARAújO, C. A. A. Correntes teóricas da ciência da informação. Ciência da Informação,Brasília, v. 38, n. 3, p. 192-204, set./dez. 2009.

ASSOCIATION OF COLLEGE AND RESEARCH LIBRARIES. Framework for Information Literacy for Higher Education. 2016.

BARRETO, A. A condição da informação. São Paulo em Perspectiva, v. 16, n. 3, p. 67-74,2002.

BAWDEN, D. Information and digital literacies: a review of concepts. Journal of Documentation, v. 57, n. 2, p. 218-259, 2001. 
BELKIN, N. Anomalous States of Knowledge as a basis for Information Retrieval. Canadian Journal of Information and Library Science, v. 5, n. 1, p. 133-143, 1980.

BEZERRA, A. C.; SCHNEIDER, M.; BRISOLA, A. Pensamento reflexivo e gosto informacional: disposições para competência crítica em informação. Informação e Sociedade: Estudos, v. 27, n. 1, p. 7-16, jan./abr. 2017.

BICUDO, M. A. V. Sobre a Fenomenologia. In: BICUDO, M. A. V.; ESPOSITO, V. H. C.(Orgs.). Pesquisa Qualitativa em educação: um enfoque fenomenológico. Piracicaba:

UNIMEP, 1994. p. 15-22.

BIESTA, G. Have lifelong learning and emancipation still something to say to each other? Studies in the Education of Adults, Leicester, v. 44, n. 1, jan./jun. 2012.

BOON, S. ; JOHNSTON, B.; WEBBER, S. A phenomenographic study of English Faculty's conceptions of information literacy. Journal of Documentation, v. 63, n. 2, p. 204-228, 2007.

BUCKLAND, M. Information as Thing. Journal of the American Society for Information Science, v. 42, n. 5, p. 351-360, 1991.

CAMPELLO, B. S. O movimento da competência informacional: uma perspectiva para o letramento informacional. Ciência da Informação, Brasília, v. 32, n. 3, p. 28-37, set./dez. 2003.

CAPURRO, R. Epistemologia e ciência da informação. Tradução de Ana Maria Rezende Cabral, Eduardo Wense Dias, Isis Paim, Ligia Maria Moreira Dumont, Marta Pinheiro Aun e Mônica Erichsen Nassif Borges. In.: Encontro Nacional de Pesquisa em Ciência da Informação, 5, 2003, Belo Horizonte. Anais... Belo Horizonte, UFMG, nov. 2003.

CARDOSO, A. M. P. Retomando possibilidades conceituais: uma contribuição à sistematização do campo da informação social. Revista da Escola de Biblioteconomia da UFMG, Belo Horizonte, v. 23, n. 2, p. 107114, jul./dez. 1994.

CAREGNATO, S. E. O desenvolvimento de habilidades informacionais: o papel das bibliotecas universitárias no contexto da informação digital em rede. Revista de Biblioteconomia \& Comunicação, Porto Alegre, v. 8, p. 47-55, jan./dez. 2000.

CERBONE, D. Fenomenologia. 3. ed. Petrópolis: Vozes, 2012. 
DARTIGUES, A. O que é a fenomenologia? 32. ed., São Paulo: Moraes, 2013.

DE LUCCA, D. M.; VITORINO, E. V. O desenvolvimento da competência informacional dos idosos: um olhar para as necessidades informacionais desses indivíduos. In.: Encontro Nacional de Pesquisa em Ciência da Informação, 26, 2015, João Pessoa. Anais... João Pessoa: LTi Laboratório de Tecnologias Intelectuais, 2015.

DOYLE, C. S. Outcome measures for Information Literacy within the National Education Goals of 1990. Final Report to National Forum on Information Literacy, June 24, 1992. Disponível em: http://files.eric.ed.gov/fulltext/ED351033.pdf. Acesso em: 13 out. 2017.

DOYLE, A. ; BEZERRA, A.C. (In)Formação e cultura nas escolas ocupadas no Rio de Janeiro. Pesquisa Brasileira em Ciência da Informação e Biblioteconomia, João Pessoa, v. 11, n. 2, p. 194-203, 2016.

DUDZIAK; E. A. ; GABRIEL, M. A. ; VILELLA, M. C. O. A educação de usuários em bibliotecas universitárias frente à sociedade do conhecimento e sua inserção nos novos paradigmas educacionais. In.: Seminário Nacional de Bibliotecas Universitárias, XI, Florianópolis, 2000. Anais... Florianópolis, FEBAB, 2000.

DUDZIAK, E. A. A information literacy e o papel educacional das bibliotecas. 2001. 173 f. Dissertação (Mestrado), Escola de Comunicação e Artes (ECA), Universidade de São Paulo (USP), São Paulo, 2001.

DUDZIAK, E. A. Information Literacy: princípios, filosofia e prática. Ciência da Informação, Brasília, v. 32, n. 1, p. 23-35, jan./abr. 2003.

DUNNE, E. The learning society: international perspectives on core skills in highereducation. Londres: Nova York: Routledge, 2013.

ELMBORG, J. Critical information literacy: Definitions and challenges. In: WILKINSON,

C. W.; BRUCH, C. (Orgs.). Transforming information literacy programs: Intersectingfrontiers of self, library culture, and campus community (pp. 75-95). Chicago, IL:Association of College \& Research Libraries, 2012.

FERRAZ, M. S. A. Lições do mundo-da-vida: o último Husserl e a crítica ao objetivismo. ScientleStudia, São Paulo, v. 2, n. 3, p. 355-372, 2004.

FIGUEIREDO, M. F. Ferramentas no julgamento avaliativo em ambiente web para buscas com vistas ao desenvolvimento de competência crítica 
em informação. Conhecimento em ação, v. 1, n. 2, p. 99-110, jul./dez. 2016.

FORSTER, M. Phenomenography: a methodology for information literacy research. Journal of Librarianship and Information Science, v. 48, n. 4, p. 353-362, 2015.

FREIRE, G. H. A. Ciência da Informação: temática, histórias e fundamentos. Perspectivas em Ciência da Informação, Belo Horizonte, v. 11 , n. 1, p. 6-19, jan./abr. 2006.

GANDRA, T. K.; DUARTE, A. B. S. Estudos de usuários na perspectiva fenomenológica: revisão de literatura e proposta de metodologia de pesquisa. Informação e Sociedade: Estudos, v. 22, n. 3, p. 13-23, set./dez. 2012.

GASQUE, K. C. G. D. Letramento informacional: pesquisa, reflexão e aprendizagem. Brasília: Editora FCI/UnB, 2012.

GIDDENS, A. Algumas escolas da teoria social e filosofia. In.: GUIDDENS, A. Novasregras do método sociológico: uma crítica positiva às sociologias interpretativas. Lisboa:

Gradiva, 1996.

GONZÁLEZ DE GÓMEZ, M. N. Novos cenários políticos para a informação. Ciência da Informação, Brasília, v. 31, n. 01, p. 27-40, jan./abr. 2002.

GREGORY, L.; HIGGINS, S. Information literacy and social justice: radical professional praxis. Sacramento: Library Juice Press, 2013.

HESSEN, J. Teoria do conhecimento. São Paulo: Martins Fontes, 2012.

HORTON JÚNIOR, F. H. Overview of Information Literacy Resources Worldwide. Paris: UNESCO, 2013.

HUSSERL, E. Meditaciones Cartesianas. Tradução de José Gaos Miguel Garcia. México: Fondo de Cultura Econômica, 1996.

INGWERSEN, P. Conceptions of Information Science. In.: VAKKARI, P.; CRONIN, B. Conceptions of Library and Information Science: historical, empirical and theoretical perspectives. London: Taylor Graham, 1992. p. 299-312.

JOHNSTON, N.; PARTRIDGE, H.; HUGHES, H. Understanding the information literacyexperiences of EFL (English as a foreign language) students. Reference Services Review, v. 42, n. 4, p. 552-568, 2014. 
KAPITZKE, C. (In)formation literacy: a positivist epistemology and a politics of (out)formation. Educational Theory, v. 53, n. 1, p. 37-53, 2003.

LE COADIC, Y. F. A ciência da informação. Brasília: Briquet de Lemos, 1996.

LEITE, C. et al. Cenário e perspectiva da produção científica sobre competência em informação (CoInfo) no Brasil: estudo da produção no âmbito da ANCIB. Informação e Sociedade: estudos, v. 26, n. 3, p. 151168, set./dez. 2016.

LENOX, M. F.; WALKER, M. L. Information Literacy: a challenge for the future. NASSP Bulletin, v. 78, n. 562, 1994.

MARCIANO, J. L. P. Abordagens epistemológicas à ciência da informação: fenomenologia e hermenêutica. Transinformação, v. 18, n. 3, p. 181-190, set./dez. 2006.

MARTELETTO, R. Conhecimento e sociedade: pressupostos da antropologia da informação. In.: AQUINO, M. A. O campo da ciência da informação: gênese, conexões e especificidades.

João Pessoa: Editora Universitária/UFPB, 2002. p. 101-115.

MARTINS, J.; BOEMER, M. R.; FERRAZ; C. A. A fenomenologia como alternativametodológica para pesquisa: algumas considerações. Revista da Escola de Enfermagem daUSP, v. 24, n. 1, p. 139-147, abr. 1990.

MINAYO, M. C. (Org.) Pesquisa Social: teoria, método e criatividade. 29. ed. Petrópolis, RJ: Vozes, 2010.

PERRENOUD, P. et al. As competências para ensinar no século XXI : a formação dos professores e o desafio da avaliação. Porto Alegre: ArtMed, 2002.

PRAGUE DECLARATION. Towards an information literacy society. Praga: UNESCO, 2003. Disponível em:

http://www.unesco.org/fileadmin/MULTIMEDIA/HQ/CI/CI/pdf/PragueDecla ration.pdf. Acesso em: 13 out. 2017.

PINHEIRO, L. V. Campo interdisciplinar da ciência da informação: fronteiras remotas e recentes. Investigación Bibliotecológica, Cidade do México, s/n, s/p, 1998. 
PINHEIRO, L. V. Informação: esse objeto obscuro da ciência da informação. Morpheus: estudos interdisciplinares em memória social, Rio de Janeiro, v. 3, n. 4, 2004.

SANTOS, R. B. Perfil do Bibliotecário universitário: uma abordagem contemporânea sob a ótica das iniciativas formadoras de Competência em Informação (CoInfo). 2017. Dissertação (Mestrado em Ciência da Informação). Programa de Pós-Graduação em Ciência da Informação, Universidade de Brasília (UnB), Brasília, 2017.

SARACEVIC, T. Ciência da Informação: origem, evolução e relações. Perspectivas em ciência da informação, Belo Horizonte, v. 1, n. 1, p. 4162, jan./jun. 1996.

TEWELL, E. A decade of Critical Information Literacy: a review of the literature. Communications in Information Literacy, v. 9, n. 1, p. 24-43, 2015.

ZURKOWSKI, Paul. Information services environment: relationships and priorities. Washington: national commission on Libraries, 1974.

WERSIG, G.; NEVELLING, U. The phenomena of interest to Information Science. Information Scientist, v. 9, n. 4, p. 18-39, 1975. 